Taronna, A. (2016). Translation, hospitality and conflict: Language mediators as an activist community of practice across the Mediterranean. Linguistica Antverpiensia, New Series: Themes in Translation Studies, 15, 282-302.

Translation, hospitality and conflict: Language mediators as an activist community of practice across the Mediterranean

\title{
Annarita Taronna
}

University of Bari “Aldo Moro", Italy

annarita.taronna@uniba.it

This article reports on a research project that involved conducting interviews with a group of language mediators who assisted the newlyarrived migrants in Southern Italy by not only interpreting for them, but also advising and helping the "boat people" to claim and negotiate their rights in the hosting country. Interview questions addressed a range of urgent issues, many of which demonstrate how the practice of language mediation is particularly relevant in today's context of migration emergency. Indeed, it profoundly shapes how we think about terms such as language, negotiation, contact, conflict, hospitality and community, and how we consider the roles of the mediators in building effective cross-border solidarity networks in real time. However, the interview answers do not provide an idealistic and idealized vision of welcoming the other. Rather, they outline a geography of proximity marked by the ancient hospes-hostis dichotomy that connotes the complexity, the ambiguity, the uncertainty, the unpredictability and the contingency characteristic of relations with the other.

\section{Introduction}

The cultural turn in translation studies that started in the 1980s produced a shift of focus from a primarily linguistic practice, investigating the word and/or a text, to an idea of translation as an integral part of a cultural, literary, historical and ethnic-anthropological system. Of particular relevance to this shift is the increase, over the last decades, of migration flows across Afro-Mediterranean routes which have turned populations that were once relatively homogeneous into linguistically and culturally diversified "ethnoscapes".1 As a consequence, transnational contact within various cultural, economic and social contexts has reinforced interaction between languages and language groups and led migrant subjects to carry their cultural heritage with them, adapting this to local repertoires. In this light it is possible to understand the proposal of identifying new descriptions and interpretation pathways for a reality that is very close to us: by reconsidering the troubled narration ingrained on the bodies of the sea-crossers, we might begin to de-construct the dehumanizing and anti-democratic language of contemporary migration. 
The context of migration emergency taken into consideration here also includes the recent episodes linked to the flows that, since the end of August 2015, have thrown into disorder the cartography of European routes, which led to the opening of more or less well-known and hospitable passages from Italy, Greece, Serbia, Hungary to Austria, Germany and the north of Europe in general.

The development of this geopolitical scene has not only reinforced security rhetoric (e.g., "new migration crisis," "registration centres," "refugee quotas" etc.) spread by the mainstream media; it has also led interpreters, translators and mediators to face new situations and new linguistic challenges, and to negotiate intense conflicts within AfroMediterranean and trans-European migration. Starting from such premises, the theoretical reflection proposed in this article focuses on the emergence of new "translationscapes" in which an unprecedented vision of translation is taking shape: translation, now, as a linguistic practice must also be able to problematize new intercultural relations such as those established between translators, ${ }^{2}$ interpreters and mediators, on the one hand, and the newly arrived migrants in southern Italy, on the other.

\section{Translation, ethics and the politics of hospitality}

The metaphor of the bridge and of the encounter among cultures has for a long time characterized the history of translation, at least starting from the so-called "cultural turn". This turn marked the breakthrough of a phenomenology rooted in the relation with the other, involving a process of permanent and inevitable exchange that affects our daily life. At present, both the concept and the practice of translation - as well as the use of English as a lingua franca - have acquired new connotations and implications due to the recent enormous movement of migrants and refugees into and across Europe, a movement which demands clear definitions of the ethics and the politics of hospitality. An example of such new transcultural scenarios is the practice of language mediation in migration contexts, in which the state of emergency not only creates new forms of unpredictable sociality and vulnerability, but also a "community of practice" (Lave \& Wenger, 1991; Wenger, 1998) which is able to turn language and translation into the figures of hospitality theorized by Derrida (2000) and Prete (2011).

Language mediation is the translation practice that contains the most intrinsically hospitable dimension. Performed by the mediator in the presence of the other, they can look the other in the eyes and engage in the tireless exercise of listening, which is the first step towards the act of translating. In language mediation, the act of listening to sounds, thoughts and voice is different from the reading and translating of a written text because it is not limited to the intertextual dialogue with the author of the given text. Rather, language mediation is enriched by the experience of 
contact with the other, recalling what Robinson (1991) defined as "the somatics of translation" and offered as an alternative paradigm to the Western rationalist/mentalist approach that deprivileged and dehumanized the body - intuition, emotion, somatic signals - within linguistic communication. The somatics of translation contributes to the investigation of the way in which our bodies send "signals" that we recognize and respond to. Considering that translation is an intuitive process of translinguistic communication, the somatics of translation allows us to include the system of stimuli and feedback circling between the "mind" and "body", reason and feeling, during language mediation. Thus, with somatics in mind, we might discover how mediators working in contact zones of migration opt for certain words, sentences and strategies not because they are abiding by some abstract code of interiorized rules, but because they at times instinctively or empathetically respond to messages or impulses sent by the interlocutor's body, signals that indicate a certain word or sentence. The unsuitability of any mind-body dualism, as well as the natural and unspoken complicity and interaction between the two, becomes visible in an analysis of the performance of the mediator's role; it is also visible in the physicalemotive relationship established with the body of the migrant, echoing what Robinson (1991) calls "dialogical bodies". As the mediator translates for the migrant who crossed the Mediterrenean, her or his words have an evocative power: the migrant goes back in time, touching, as memories arise, original experience. Such somatic approaches to language and translation contribute to the relocation of meaning in the sphere of emotions and feelings, taking it back to the dimension of human subjectivity. To see language and translation as figures of hospitality means, for the language mediator, embracing fundamental ways of welcoming the other into her or his own world, in translation as well as in everyday life.

In the background of such an unprecedented translationscape we can evoke Prete's (in Gramigna, 2007) conception of translation as an ethical and political act, as the ability to recognise and receive the other within one's linguistic space:

Translating means to host someone, a foreigner, in one's own house. I often use the image of hospitality, an anthropological image that has to do with nomadism and Mediterraneity: the nomads hosted in their tent any traveller in transit. Nomadic hospitality presupposes a non-rooting in one place. Translation works similarly. Those who think that language is a place that only belongs to us in its partiality (because languages are plural) are more open to host another language in the home of their own language. (p. 123, my translation) 
Prete's translation poetics offers a model of intercultural relations for the language mediation practised in migration emergency contexts. Its relevance is evident in the following testimony ${ }^{3}$ by a language mediator who is describing how her activity is a practice of unconditional hospitality:

Elisa Fedele.: The right to hospitality is our ... I'd say our primary ethical principle ... the right to hospitality that then includes all the basic human rights, because anyway you are dealing with people, you are not dealing with documents, paperwork or recordings. [...] I feel like an activist because you don't do this job for the wages, absolutely. All jobs you don't do, in my opinion, only and exclusively for the wages - it's something you mustn't ... you shouldn't do just to have an income, because otherwise it's empty, absolutely empty. You miss on all the human side, although it is the ... the most important. Thus the aim is indeed to communicate with these people, understand one another, feel with each other, and ... it is indeed different from interpreting ... let's say somehow [interpreting] is cold, with an end in itself. Well [mediating] is very contextualised ... bound to the reality of what you are doing, that why you ... you can't leave when ... if your shift finishes at one and there's someone who's ill or someone that needs a pair of shoes, you can't just leave at one dead on. You must stay even until two, until four, if it's needed. You can't leave everything and say "my shift is finished. See you tomorrow at 9" for example. But if there is someone to be brought to hospital at half eight, or if an accident happens at two in the morning, you run. [...] we have to be available 24/7. I always return to the comparison with children, like looking after children. If they have problems in doing some things, in a place they don't know ... to a child you can't say ... I have no time now, I can't be bothered now ... you'll eat ... tomorrow, I'll give you the baby bottle tomorrow. If it's needed today you do it today, no matter what time it is. (personal communication, September, 2014)

Such an undeniable sense of participation and identification with the migrants at the core of the stories that mediators have to negotiate triggers a reflection concerning the relationships between translation, identity and hospitality policies in the Mediterranean (Zaccaria, 2013) and the ways in which mediators can humanize the transfer of the migrants to the numerous established reception structures. The sense of identification and involvement with the narrated and mediated migrants, with their stories and situations, leads mediators to conceive of translation as a practice of "unconditional hospitality". This is a practice that, Derrida (2000) suggests, is a way of receiving the other and reaching better forms of relations among people without asking anything in return, without raising 
barriers or building walls, without establishing inviolable rules. A practice evident in the reiterated use of expressions such as "you don't do", "you shouldn't do", "you can't simply leave". and "you can't say" in Elisa's testimony.

All of the testimonies gathered from the mediators show how hospitality is crucial not only to their mediation practice, but also to their model of plurilingual, participative and active citizenship that recalls Derrida's sense of welcoming the other with all her or his diversity, of unconditionally offering one's hand to all that is new and alien. Derrida's unconditional hospitality is particularly relevant to the contemporary debate on migration because it does not provide an idealistic and idealized vision of opening to the other; rather, it outlines the profiles of a geography of proximity marked by the ancient hospes-hostis dichotomy connoting the complexity, the ambiguity, the uncertainty, the unpredictability and the contingency of relations with the other. Thus, if, on the one hand, foreigners - the migrant for economic purposes and the asylum seeker - are provided with a ruled hospitality that depends on laws, time, state, police, the closure and the separation of spaces, on the other hand, more fluid forms of unconditional hospitality are emerging, and the practice of language mediation is one of these.

In the migration emergency context a double threshold of hospitality is coming to light. The approach of the migrant subject entering our space, appropriating our language, touching us and forcing us to change - compels the linguistic mediator who works in such dislocating contexts to transfer to the other side, to a decentred point from which she or he can observe herself or himself and the world. The mediator, positioned between languages, responds to the partiality of each language with a border trespass, thus exposing the richness entailed in language plurality. Each mediator, with her or his own story, proves how this language plurality is fundamental: without it, it would not be possible to translate, and not be possible to explore the unknown and experience the difference of the other. More specifically, it might be interesting to conceptualize language as a form of hospitality for the other, of her or his difference, of her or his distance that requires forms of responsibility towards the guest. ${ }^{4}$ All this, taking into consideration the communication and translation processes experienced by translators, interpreters and mediators during their interactions with migrants in contact zones such as those along Afro-Mediterranean routes (e.g., ports, CARA, CIE, SPRAR ${ }^{5}$ etc.), In this respect, language mediation can help to define translation as a process of mutual understanding. Mediation recalls multiple languages and stories that reinforce the awareness that it is now impossible to give up on intercultural communication, because the other is not elsewhere but contiguous. Mediation helps us enjoy the sound of the language and body of the other. In the background of such an immense human and poetic geography, the figure of hospitality can be useful in explaining the sense of the other that is at stake in translation. As Prete (2011) states: 
Men and institutions, who scattered borderlines, dividing walls, corrals and picket fences, fortunately have left languages free from defence, trespassing prohibitions, enclosures. Anyone can cross its regions, visit its rooms, draw from its treasure. A language belongs to those who share it, thus it is also of the learning foreigner, that makes it her/his own for her/his communication, narration, thoughts. [...] All that belongs to a language can be crossed. It is in the language - unfortunately at times only in the language - that a country shows its disposition to welcoming. Because the language is hospitable by its own nature. (p. 14, my translation)

Language, as well as translation, is hospitable by its own nature because we all are invited to live a broadened intimacy with the other and to welcome those who are in transit. The crossing of territories and borders, might be, as suggested by Prete, the most ancient and Mediterranean figure of hospitality: a nomad is hospitable because she or he knows the meaning of being on the road, of being exposed while transiting. Translating is welcoming in another language that is on the road. Translating is at the same time welcoming with our language, a transiting subject making sure that those who are hosted are not forced to give up on their accent, their singularity, their identity.

Today, the plurality of languages, and thus their comparison and reciprocal translation, is visible largely due to migration. The hospitality towards those who migrate, the recognition of their rights - asylum, healthcare, education, work, citizenship - also concerns language, with its baggage of identity, memory and belonging. For those who migrate, to preserve such a relationship with their native language means being able to establish connections with the inhabitants of the host country that extend from their own culture. The experience of migration dislocates people as well as languages and only the acceptance of language plurality, of the polyphony of stories, language manners, cultures, allows translating. Translating means enacting relations with the other in all of its possible figures and with all of its losses and compensations, misunderstandings, separation, dialogue, listening and unfamiliarity. In contemporary migration scenarios, full of more or less predictable conflicts and tensions, translation is a texture of sense and sound that holds in its interstices, in its at times unspeakable silences, the double threshold of a contagious and unexpected hospitality.

\section{English as a translingual practice in contact zones}

Migration involves the intense circulation of peoples, goods and cultures as well as, less explicitly, hierarchical and hegemonic power relations between territories and their inhabitants. Languages, and the borders they establish, are essential to such movements and relations. But no language 
is innocent or neutral, because it reflects and structures our ideology and worldviews. In this light, as Määttä (2015) suggests that a critical reflection about the nature and function of language and multilingualism and the consequences of language use in interpreter-mediated communicative encounters is necessary in order to allow the interpreter to occupy subject positions from which power relations can be negotiated and linguistic equality delivered. This is particularly easy to observe when taking into consideration the use of English as a lingua franca in language mediation. As the Australian linguist, Alastair Pennycook (1994), has argued, in the context of globalization, English has created asymmetrical relationships:

Its widespread use threatens other languages; it has become the language of power and prestige in many countries, thus acting as a crucial gatekeeper to social and economic progress; its use in particular domains, especially professional, may exacerbate different power relationships and may render these domains more inaccessible to many people; its position in the world gives it a role also as an international gatekeeper, regulating the international flow of people; it is closely linked to national and increasingly non-national forms of culture and knowledge that are dominant in the world; and it is also bound up with aspects of global relations, such as the dominance particularly of North American media. (p. 13)

Most criticism of linguistic imperialism focuses on the socio-cultural implications intrinsic to the global spread of English. While the development of transnational, English-speaking elites isolate those who cannot speak the language, at the same time linguistic and cultural homogenization (regardless of the language spoken) consequently pushes minor languages and cultures towards extinction. The origin of the global spread of English is intertwined with British colonial expansion that, by the end of the nineteenth century, had reached every continent and created a global network of trade, transport and communication. This network was made possible by technologies developed during the Industrial Revolution and laid the foundation for our current global economy. By the mid-twentieth century, English was common even in those countries, such as many in Europe, which were not directly involved in British colonialism, thus becoming part of what Kachru (1990) defined as the "expanding circle". While travelling around the world, English has brought to light a great number of varieties, some of which are nowadays generally recognised and taught as standard (American English, Australian English), with others (African American English, Indian English, Jamaican English, etc.) on the way towards recognition and standardization. 
The present situation for English expansion is not as it was during colonialism because English varieties are now disrupting efforts at standardization. In particular, because of innovations in communication technology, increasing migration flows and transnational interests that are leading to new contacts between people with different linguistic and cultural heritages, English has become the lingua franca of international communication. Thus, this research specifically investigates the possibility of developing ELF (English as a Lingua Franca) communication that can be recognised and even shared by both western mediators and non-western migrants. With this purpose, it might be worth specifying that "ELF" is a term that encompasses "the conventional notion of 'fossilized interlanguages', as well as of those varieties of English defined as pidgin and creole" (Guido, 2008, p. 24). But that seems to be evolving towards what Canagarajah (2013) defines as a form of "translingual practice" - a practice that, although recognizing norms and conventions established by dominant institutions and social groups within given contexts, is more closely focused on the fact that the speakers can negotiate such norms according to their own repertoires and translingual practices. In this regard, since varieties of English are not necessarily in conflict with one another but desirably complementary, their interrelation has to be tied in more dynamic terms - abandoning the duality intrinsic to labels such as mono/multi, mono/pluri and mono/poli.

The hybrid, permeable and translingual nature of ELF is experienced by numerous Italian language mediators. Elisa Fedele describes it in particularly meaningful terms:

The English language we use to communicate with the migrants is necessarily a simple one but also a mixed code composed of some words or expressions from other languages (ex.: French, Spanish or even Arabic) (personal communication, September, 2014)

This brief statement echoes Canagarajah's (2013, p. 2) "motto": according to him "we are all translinguals" in contact zones. That is, we speak a flexible, contingent, unstable bridge language that is suited to the co-operative co-construction of meaning, and that leads to successful intercultural communication. A consequence of this practice is not only the sense of ease and familiarity that Italian and non-Italian mediators feel about the lingua franca, but also the creation of hybrid and inclusive language formulas resulting from contact with other languages, reterritorialization needs, and the will of the speakers.

The use of ELF in mediation within migration contexts can also entail asymmetric and conflictual interactions when, for example, mediators clearly state that they perceive English as a barrier in the construction of a relationship and an immediate interaction with the migrant. In such cases, the knowledge and use of the migrant's native language is better at 
creating a bridge for communication, as we see in the following testimony:

Wasim Alkahlout:: There are positive aspects in being their fellow countrymen, or at least to speak their same language. [...] they have come crossing the Mediterranean, in such a difficult and dangerous situation [...] and then when they see me - or another mediator waiting for them at the port and they realise I speak Arabic they are relieved and say things like "Finally someone speaks our language!", a good part of them come from poverty, they haven't studied and they can't speak English, they are in real trouble [...] once one of them said to me "you are like a ton of gold" because you make them feel as if ... as if they are home, even if just for a second. Even if they are not. [...] Language is not everything: it is fundamental to know and respect their culture, otherwise you won't be able to avoid clashes. (personal communication, September, 2014)

This statement is interesting not only in terms of its narrative; it reveals how the personal experiences of the mediator inform but perhaps also complicate the practice of mediation. The statement also refers specifically to the role of the migrant's mother tongue as the main repository of a community's common sense that constitutes a shared stock of meaning enabling its speakers not only to make coherent sense of the world, but also to understand and handle possible conflict beyond the limits of English (Cohen, 2001, pp. 26). However, we also need to assume that in migration emergency situations language mediators are generally recruited "last minute" and interpreting service providers do not have much time to find professionals who are able to speak different native languages in addition to Arabic (i.e., Trigrinya, Dari, Pashto, Swahili, etc.). Consequently, in these vulnerable situations English - as well as French - is used as a language of contact no longer embedded in one national framework or in a strict set of standard rules, but in multiple nuances in terms of phonetics, lexicon and morpho-syntax due to contamination by global cultural flows.

Following this logic, as suggested by Canagarajah (2013), we should consider English as a contact language that needs to be regarded as a variety in its own right, moving and transforming along with the migration flows of subjects transiting in border zones and who resort, in their interactions with language mediators, to personal English varieties. Such considerations inevitably recall Pratt's (1987) idea of "contact linguistics". Pratt suggests that we allow the formation of new geolocalities and new language policies in the light of the numerous contaminations by global cultural flows of escapees from neo-colonial dystopias and hegemonic discourses of abuse and language extinction, and that we embrace new practices of linguistic and cultural crossing. The 
hypothesis implicit in this article is that the recovery of 'situatedness' (Gumperz, 1982) - the contextualization of the interactions between migrants and mediators and the recognition of their socio-cultural contexts and pragmatic-linguistic dimensions - gives sense to mutual understanding and to a transcultural exchange between the participants.

As stated by Guido (2008, p. 26), this awareness can guarantee communicative success that is essential in specialist interaction domains such as those related to language mediators interacting with non-Western migrants. In cases such as this, the dialogic co-construction of an ELF discourse that is accessible and acceptable for the non-western participant can be obtained through linguistic and extra-linguistic strategies that mediators can adopt during migration emergencies not only for communicative purposes, but also to humanize the transfer of the migrants to the various reception or detention camps scattered across Italy.

More specifically, Meierkord (2004, p. 128) has identified the following language features generated in contact zones: total correspondence to the rules of L1 English varieties; transfer phenomena, development models and nativized forms; and simplification, regularization and levelling processes. Among such phenomena, lexical and morpho-syntactic simplifications are the most common, as witnessed by Elisa Fedele:

Elisa Fedele: I studied Engish at school and at university, but when we speak with the guests we need to simplify it ... very much. Actually there are few people who speak, how can I say, the standard French. Or, for example, the Nigerian English is quite different from the standard English that we study at school or at university. We definitely simplify our language as much as we can, and sometimes we ask for help [from] those people who can speak a more standard French or English and thus can act as interpreters for those guests who almost know the lingua franca. (personal communication, September, 2014)

Simplification is but one of the language accommodation strategies adopted to ease communication, to enhance understanding or to resolve conflict. Other strategies include morphological adaptation through the use of simple grammar structures, lexical repetition promoting clarity and unambiguous messages (Mauranen, 2007), reassuring voice tone and pronunciation, slower elocution and lengthening of both utterances and pauses (Rudvin \& Spinzi, 2013).

However, accommodation strategies also include extra-linguistic components such as body language (e.g., smiling eyes, body positioning, gestures, facial expressions) and behaviour - for example, when ignoring (standard violating) 'mistakes' and redundancies. Hesitations and silences are often used strategically, too, because they are helpful when amending, 
clarifying or contextualizing a misunderstanding, according to what Firth (1996) defined as 'let it pass' and 'make it normal' principles. Actually, when answering the question "what strategies do you use to mark respect or authority?", most of the interviewed mediators stated that one of the affective aspects of the discourse is reassuring the interlocutor using eyes, tones and hands, thus easing the process of negotiation, which contributes to mutual intelligibility.

Both linguistic and extra-linguistic strategies enhance the role of linguistic mediation in contact zones as collaborative negotiation practices that do not necessarily imply a vision of contact as harmonic, neutral or apolitical. Contact zones as border zones are places where it is possible to experience both a dynamic and cultural exchange and the power asymmetries that make the interacting subjects' experiences conflicted and even painful. In fact, the combination of such linguistic and extra-linguistic elements also serves to mediate the high level of emotional stress that is common in reception or detention camps where the migrants, having just arrived in Italy, are gathered, processed and forced to face, according to Agamben (2003/2008), a "state of exception". ${ }^{6}$ The use of English as a contact language in mediation, as enacted in a migration emergency context, also suggests another recent theoretical paradigm articulated by the Japanese sociologist, Yukio Tsuda (2008). Tsuda describes a global society, hierarchically structured, on the top of which are the L1 English speakers, followed by L2 speakers, and speakers of English as a foreign language. At the bottom are those who cannot speak English at all. In particular, to contrast the threat represented by the use of English as a hegemonic language, Tsuda proposes a model defined as "the ecology of languages"7 that requires an education towards multilingualism through efficient and democratic strategies - such as some of those already discussed - aimed at promoting English as a lingua franca without necessarily neutralizing the presence of other languages and cultures. This would provide the speakers with an awareness of equality in communication, language rights, and of cultural and linguistic pluralism.

\section{Preserving contact and negotiating conflict: Language mediators in migratory emergency settings as an activist community of practice}

This last section examines some of the most relevant testimonies that are crucial to the investigation of what language and cultural mediation meant to mediators before and after their experience with the migrants in the settings of emergency and first reception. Before their work with migrants in southern Italy, most of the mediators had practised translation for professional purposes, developing technical skills or for training experience, as in vocational postgraduate courses. However, after their experience as language mediators in migratory emergency settings most 
of them felt engaged in a collective project and feel that the work they do has an intercultural and political agenda that transcends the conventional idea of translation as a mere linguistic transfer tool. In particular, they realised that their new conception and practice of translation was starkly restricted by the behavioural protocol established by local police and other law-enforcement agencies, who dictate the camp rules in the detention and reception centres. Such challenges to the practice of translation are evident in the following excerpts:

Bassam Elsaid ${ }^{8}$ : The experience in Lampedusa was brilliant, even if wearing. I couldn't sit for up to 70 hours, with no sleep. I learnt much more in those days in the field than in 3 years of academic studying. [...] Among all the people I met, I remember two young Tunisian men in particular: One was proficient in English and French and was a volunteer for the Red Crescent Movement; when he arrived he started helping out with us. The other one was a mechanical engineer who fixed the electrical generator which had broken; when the light worked again all his fellow countrymen applauded. (Italian Red Cross, n.d.).

Giuseppe Ponzio: The perverse process combining my need of income, the state of emergency, and the needs of the contracting service provider couldn't but lower the professional expectations of the staff, including my own. I had never served in this kind of organisation, never worked in an immigration reception centre, as I was just a student attending Università del Salento Master's program in Intercultural Mediation in Lecce, and my only competence - since I spoke no French - was knowledge of Classical Arabic and Egyptian dialect. Until then, I had always thought that a good translation required a strong knowledge of both source and target languages and cultures. But then the "camp" rules came along and changed my - a bit too academic - belief about the translator as a mediator [...] On the morning of March 31 st, one of the Connecting People managers came to explain to us our duties. He said: "Our role is to be with the immigrants all the time. We are the closest people for them and we have to clarify that, if they run away, they will not be entitled to benefit from any legal rights and will become undocumented immigrants. We cannot force them to stay, but we can advise them against leaving. The lawyers will have to be really thorough in illustrating to them the applicable judicial system on the subject of immigration. The mediators must act in a co-ordinated way, must not take any personal initiative nor spread information they are not sure about and must be available for meetings with the guests to explain to them the rules in the CAI (Centro accoglienza e identificazione/Identification and reception centre). The operators 
will have to keep clean the tents, common areas, and toilets, and will be in charge of distributing the meals. It is necessary to demonstrate full collaboration with the law-enforcement agency. I don't want Tunisian citizens to feel imprisoned in any kind of way. We need to respect them, but at the same time it is necessary for them to respect the rules of the camp for peaceful coexistence. It is necessary to treat them in a human way at all times. (2012, pp. 8485 )

The covert institutional expectation of neutrality - as reported in Giuseppe Ponzio's testimony - is a common and controversial feature experienced by most of the interviewed mediators. This conflict between neutrality and advocacy, most of the mediators said, broke the somewhat idyllic picture of language and cultural mediation they imagined prior to their work in southern Italy. The concept of translation that the mediator has to face is "new" in the way that it breaks the traditional view of the intercultural harmonious dialogue by revealing its controversial nature in the tension between what the translator as mediator wants to do/say/translate and what she or he really can do, say or translate. More specifically, this new idea of translation reflects both an unspecified code of professional ethics and the vagueness of national guidelines concerning the mediator's task. ${ }^{9}$ Among the other variables which come into play in what Merlini (2009, p. 59) calls a "mediation zone", a socialization process of translation practices and strategies occurs within the mediators' community. This process is made explicit in the following testimonies which concern whether mediators get used to talking, exchanging ideas or having relationships with other colleagues and whether they perceive themselves as belonging to a community of activists who share the pros and cons of the work they do. The related replies by Wasim Alkahlout and Elisa Fedele, who both work as mediators at Salam, are particularly relevant to this discussion:

Elisa Fedele: It often happens to me, for example after a difficult period or an unusual day of mediation, to look for other mediators to meet with, to share the hard times, the problems, the states of mind, well, the strategies, to find in the other mediators a small sharing community, a small network to share the work and all the set of problems linked to the work: from the stories of the people to the language hurdles. I think that only those who live specific experiences with you can somehow help you, maybe in a moment of doubt or even of downturn, ... a psychological weakness. Like ... surely you turn to ... people who know the reality you talk about, and all the rest, all the context, all that's behind it. (personal communication, September, 2014) 
Wasim Alkahlout: We collaborate much while we work; we pass things on to each other, I pass things on to Elisa, or if there's any mediator in trouble or in some situation, we are always together, always complementary. (personal communication, September, 2014)

Collaboration and solidarity among the language mediators are particularly helpful not only in some difficult language interactions where words sometimes are not enough for explaining and translating the traumatic experience of the sea-crossing or of the detention in the camps, but also when they feel so emotionally involved that they come to subscribe to or empathize with the migrants' stories they translate, interpret, or mediate. In this light, the following testimonies of Giuseppe Ponzio, Bassam Elsaid, Elisa Fedele and Wasim Alkahlout reply to the questions about whether they have ever perceived such an overwhelming empathy as an obstacle to mediation and about what they think about the principle of neutrality advocated by many institutions that usually discourage "taking a stance" in the work of mediation:

Giuseppe Ponzio: You would identify with them so much that you would "suffer" because you could not know how their stories would end or when the first permits would arrive. $(2012$, p. 88)

Bassam Elsaid: When a pontoon docks in Lampedusa, the migrants are happy to hear someone speaking Arabic. They feel heartened and reassured. This happens every time a rust bucket arrives, full of people looking for opportunities. I play the delicate role of "translator" not only of procedures and rules, but also of feelings and pain, and this first reception contact is an overwhelming experience. (Italian Red Cross, n.d.).

Elisa Fedele: There are stories and situations in which you start feeling a strong empathy, in which one would want to do something different or more than one should. But then you get stopped by the circumstances, by what the reality you live in actually is. And then maybe you cannot give the migrant the answer you would want to, because on the other hand you have, for example, the Immigration Office that imposes on you not to say certain things or does not allow you to do some things maybe [...] And then there is the moment of familiarity, of familiar chatting, and one can indulge in the empathy, and ... many times it's a bit like ... like educating children. Well, I mean that anyway you can't always say yes, for example. There's also the time when you need to answer no to some request, even if as a person, beyond your role, you would want to say yes, but you cannot do it. And so you are obliged not to do it. There are many situations ... (personal communication, September, 2014) 
Wasim Alkahlout: When I started my job, I felt much empathy and also pain because I didn't feel free to do or say what I wanted, because, according to the law, this is forbidden, for example. Because, well, there's the figure of a provincial assessor, don't know ... that tells you "no, you can't say this", there's the figure of a police officer that says "no, you can't do this", there's the figure of a ... UN or UNHCR, don't know ... Save the Children ... they all exist, the prefecture, the police headquarters, there are some things you can't do, then with time ... well, you get used, one gets used and knows what ... but I feel free in general. (personal communication, September, 2014)

As we see in these statements, in listening to the narration of the migrants' sea-crossing experience, of their individual challenges, of their personal suffering and fear and apprehension, the language and cultural mediators use their linguistic skills to offer narrative space for the testimony, a space which can then become a site for resistance and for empathy (Baker, 2013). Crucially, according to many foreign mediators, such empathetic relationships are further complicated by the very fact of having been a migrant, an experience which gives the mediator an understanding of both the psychological and the practical difficulties of the state of migrancy. Indeed, as Rudvin and Tomassini (2007, p. 252) suggest, the mediators are often prompted by their own experiences of migration and the hardships and/or practical difficulties they themselves experienced when they first migrated, leading them subsequently to share what they have learned about the country with their co-nationals or comigrants. But as Elisa and Waseem reveal, empathy can sometimes be unfruitful as it engenders in the migrant the expectations that the mediator will act as an ally, advocating her or his interests against those of the institution.

This undeniable sense of participation and identification with the migrants as protagonists of the mediated stories, topics and situations also triggers a reflection on the extent to which mediators can humanize the migrants' transfer to, and internment at, the different detention centres across Italy. Indeed, a quick look at the literature on language and cultural mediation (Gavioli, 2014; Rudvin \& Spinzi 2013) reveals that forms of mutual solidarity, more direct contact and interest in the migrants' lives are enabled and enhanced by various acts of translation as explained by Giuseppe Ponzio and Wasim Alkahlout in their reply to questions on whether they can conceive of their language and cultural mediation as an activist practice of unconditional hospitality:

Wasim Alkahlout: I feel like an activist because ... especially for me who's always going everywhere ... we take care of many immigrants in many reception centres in the Taranto area ... that doing ... many things in this centre, that go from that place to that 
other one, they call you from somewhere that there's a problem "come here, please, we cannot communicate ... come here, do" and then I'm back here to work ... I feel like I am ... yes, an activist. It has nothing to do with ... many times it has nothing to do with it, you don't feel like you are a cultural mediator anymore, you are doing ... as you said, yes. You're being an activist. (personal communication, September, 2014)

As demonstrated by the testimonies discussed so far, there is a sense of an ideal aspiration towards the construction of a "mediation zone", where mutually enriching exchanges between migrants and natives may bring about social change and cultural transformation. Here both the foreign mediators" "natural" belonging to the ethnic communities and the native mediators" "mimetic" effort to understand the existential plight ${ }^{10}$ caused by dispacement are seen as crucial factors in their ability as translators to act as human bridges (Merlini, 2004). This sense of participation together with the narrated or translated migrants, topics and situations enables the language mediators to construct not only translation(s) as narratives by which they can negotiate their way in the world (Baker, in Baker \& Chesterman, 2008, p. 22). It also leads to the creation of a community of practice (Lave \& Wenger, 1991; Wenger, 1998) held together by a sense of hospitality that is crucial to both their mediation and to their model of plurilingual, participative and active citizenship.

\section{Concluding remarks}

The research findings in this paper suggest that the process and the experience of mediating in a situation of migration emergency profoundly shapes how we think about terms such as language, negotiation, contact, conflict, hospitality and community, and how we consider the roles of the mediators in building effective cross-border solidarity networks in real time. In the light of such conditions and discursive relationships, this article has attempted to show how translation is a complex intercultural practice that opens the window onto the controversial politics of hospitality and an ethics of hospitality which are contingent upon local practices, as demonstrated by the testimonies of the mediators working with the newly arrived migrants in southern Italy. Indeed, while mediators working in southern Europe face large populations of migrants coming by boats, often in extremely traumatizing circumstances, interpreters in northern Europe work with migrants who typically arrive in smaller groups or alone, in circumstances that are less dramatic. Furthermore, this research has also focused on the use of English as a Lingua Franca in the practice of language mediation and on the role this language may display either as a barrier or as a bridge. The perceived role of language therefore affects the relationship between the mediator and 
the migrant and the manner in which a politics of hospitality is shaped in the Mediterrean littoral.

The question of extending the use of EFL could perhaps look more into the problem of making such a choice in that it may limit mutual understanding since it would, in non-English-speaking environments, create a socio-cultural "void". Such a lacuna might be an obstacle to understanding, despite any extralinguistic strategies that might be adopted. In particular, since migration has strongly contributed to the acquisition and use of English as a first, second or foreign language and to the burgeoning of new Englishes all over the world, the traditional knowledge of language as a social projection of territorial unity held together by shared behavioural norms, beliefs and values has been problematized. Furthermore, the alternative paradigm of English as a translingual practice in contact zones has been introduced.

Finally, the provisional findings suggest that the interviewed mediators construct a community of activists who work as a "living" network of actors. These actors can increasingly create distinctive, autonomous spaces to experiment with translation as a radical or subversive enactment of citizenship in itself, with the prospect of envisioning new wor(l)ds and new balances of power.

\section{References}

Agamben, G. (2003). Stato di eccezione. Torino: Bollati Boringheri [English translation: State of exception. Chicago: University of Chicago Press, 2008].

Appadurai, A. (1996). Modernity at large: Cultural dimensions of globalization. Minneapolis, MN: University of Minnesota Press.

Baker, M. (2006). Translation and activism: Emerging patterns of narrative community. The Massachusetts Review, 47(3), 462-484.

Baker, M. (2008). Ethics of Renarration - Mona Baker is Interviewed by Andrew Chesterman, Cultus 1:1, 10-33., available at http://www.monabaker.com/ documents/CULTUSInterviewFinal.pdf

Baker, M. (2013). Translation as an alternative space for political action. Social Movement Studies: Journal of Social, Cultural and Political Protest, 12(1), $23-47$.

Canajarajah, S. (2013). Translingual practice. Global Englishes and cosmopolitan relations. London: Routledge.

Cohen, R. (2001). Language and conflict resolution: The limits of English author(s). International Studies Review, 3(1) 25-51.

Derrida, J. (2000). Hostipitality. In Angelaki: Journal of the Theoretical Humanities, Vol. 5, Num. 3, December 2000.

Firth, A. (1996). The discursive accomplishment of normality: On 'lingua franca' English and conversation analysis. Journal of Pragmatics, 26, 237-259.

Gavioli, L. (2014). La mediazione linguistico-culturale: Una prospettiva interazionista. Guerra edizioni: Perugia. 
Gramigna, V. (ed.) (2007). Interview with Antonio Prete. In Tradurre. Voci dagli «altri ». Bari: Edizioni B.A. Graphis, 123-130.

Guido, M. (2008). English as a lingua franca in cross-cultural immigration domains. Bern: Peter Lang.

Gumperz, J. (1982). Discourse strategies. Cambridge: Cambridge University Press.

Italian Red Cross, (n.d.). (ANSA) Volontario egiziano, a Lampedusa 70 ore senza dormire. Mediatore culturale della CRI, "tranquillizzo parlando in arabo". Retrieved from http://www.cri.it/flex/cm/pages/ServeBLOB.php/L/IT/ IDPagina/7825.

Kachru, B. (1990). The alchemy of English. Chicago, IL: University of Illinois Press.

Lave, J., \& Wenger, E. (1991). Situated learning: Legitimate peripheral participation. Cambridge: Cambridge University Press.

Määttä, S. (2015) Interpreting the discourse of reporting: The case of screening interviews with asylum seekers and police interviews in Finland. The International Journal of Translation and Interpreting Research, 7(3), 21-35.

Mauranen, A. (2007). Hybrid voices: English as the lingua franca of academics. In K. Føttum (Ed.), Language and discipline perspectives on academic discourse (pp. 243-259). Newcastle: Cambridge Scholars.

Meierkord, C. (2004). Syntactic variation in interactions across international Englishes. English worldwide, 25(1), 109-132.

Merlini, R. (2009). Seeking asylum and seeking identity in a mediated encounter. Interpreting, 18(1), 57-92.

Pennycook, A. (1994). Cultural politics of English as an international language. London: Longman.

Ponzio, G. \& Quarta, Elisabetta (2012). Cap III Il non luogo dell'“accoglienza”: il CAI di Manduria In A. Ciniero, E. Quarta \& M.Tritto (Ed.), Le pratiche locali dell'accoglienza. Le politiche pubbliche locali e l'atteggiamento delle comunità locali di fronte al fenomeno immigratorio in provincia di Brindisi: le possibili vie del dialogo (pp. 66-97). Lecce: International Centre for Interdisciplinary Studies on Migration and University of Salento Press.

Pratt, M. L. (1987). Linguistic utopia. In N. Fabb, D. Attridge, A. Durant, \& C. MacCabe (Eds.), The linguistics of writing: Arguments between language and literature (pp. 48-66). Manchester: Manchester University Press.

Prete, A. (2011). All'ombra dell'altra lingua: Per una poetica della traduzione. Torino: Bollati Boringhieri.

Renzetti, R., \& Luatti, L. (2001). Facilitare l'incontro: Il ruolo e le funzioni del mediatore linguistico-culturale. Rome: Jacaranda.

Robinson, D. (1991), The translator's turn. Baltimore, MD: The John Hopkins University.

Rudvin, M., \& Spinzi, C. (2013). Mediazione linguistica e interpretariato: Bologna: Clueb.

Tsuda, Y. (2008). The hegemony of English and strategies for linguistic pluralism: Proposing the ecology of language paradigm. In M. K. Asante, Y. Miike, \& J. Yin (Eds.), The global intercultural communication reader (pp. 167-178). London: Routledge. http://miresperanto.com/en/english_as_intern/hegemony _of_english.htm 
Wenger, E. (1998). Communities of practice. Cambridge: Cambridge University Press.

Zaccaria, P. (2013). The art and poetics of translation as hospitality. In T. Claviez (Ed.), The conditions of hospitality, ethics, politics, and aesthetics on the threshold of the possible (pp. 168-184). New York, NY: Fordham University Press.

1 The term "ethnoscapes" refers to the neologism coined by Appadurai in Modernity at Large (1996, p. 45) and to the suffix "scapes" used in the anthropology of globalization to describe the transnational distribution of certain elements (e.g., technological, financial, of media resources) that outline the different "land-scapes" of the contemporary world. According to Appadurai (ibid.), the world we live in is constantly crossed by a series of flows that he defines as "ethnoscapes", "mediascapes", “financescapes", "technoscapes" and "ideoscapes". Such flows can be considered the result of what globalization has brought to every place in the world, and what Appadurai defines as "modernity at large".

2 Since my analysis focuses on the language of mediation, I will hereafter use the term "mediator" to describe the translator, interpreter and cultural mediator. This paper does not tackle the debate on the distinctions between these three roles. However, for further discussion on this topic see Renzetti and Luatti (2001) and Merlini (2009).

3 This research project is based on a larger corpus of interviews conducted from September 2014 to July 2015. The interviewed mediators were selected according to two criteria: (a) work experience in conditions of migration emergency; and (b) shared migratory history and similar experiences relating to the period of migration and settlement in Italy. By piecing together their profiles, we can assume that the volunteers fall into three categories: the native informant working within a given ethnic community and providing "inside" information; less experienced and amateur bilingual translators and interpreters (including students of translation, interpreting and language-related disciplines); a wide range of activists working in the field of humanitarian, international and intercultural co-operation, foreign affairs and diplomacy, and migration policy. All of the mediators belong to either local (e.g., Associazione Salem, CoopAuxilium) or national (e.g., Connecting People, Arci, CRI, CIES) non-profit humanitarian organizations. Specifically, the excerpts presented in this research refer to Wasim Alkahlout (a Palestinian mediator from Gaza and a former seacrosser. He obtained a degree in English Language at the University of Alazhar in Gaza and completed a Euro-Mediterranean Master Course at the University of Bari) and Elisa Fedele (an Italian mediator who took part in the reception activites related to the North African emergency in 2011). Both work as language mediators for Salam Association, an NGO based in Martina Franca (Taranto, Italy) that co-operates with the Mediterranean basin's peoples. 
4 A thorough reading of Italian law will show how the legislator more or less consciously made a meaningful and yet ironic terminological choice. In all legal documents and codes, the foreigner kept in detention centres is always defined as an ospite (guest). In the current Italian, an ospite receives hospitality: such people are welcomed as friends or acquaintances (but they can also be foreigners or strangers). This clearly is the meaning the Italian legislator had in mind when identifying the migrants who were transferred into the very first Centri di Permanenza Temporanea e Assistenza (Centres of Temporary Stay and Assistance) established in Italy in the late 1990s. Irony is intrinsic when defining as ospite/guest - a group of people who are subjected not only to serious limitations on their personal freedom, but even deprivation of their very human rights.

5 CARA is the acronym for the Italian Reception Centre for Asylum Seekers; CIE is the acronym for the Italian Centre for Identification and Expulsion; SPRAR is the acronym for the Protection System for Refugees and Asylum Seekers.

6 From a theoretical point of view, the "state of exception" represents the inclusion and capture of a space that is neither outside nor inside, a space that corresponds to the annulled and suspended norm and that creates a permanent state of emergency (Agamben 2003/2008).

7 More specifically, Tsuda's research sharply expressed, through two opposite paradigms, multiple dimensions of linguistic policies. To the paradigm of the global expansion of the English language he associates the following phenomena: capitalism, science and technology, modernization, monolingualism, globalization and ideological internationalization, transnationalism, the Americanization and homogenization of world cultures, linguistic, cultural and media imperialism. On the contrary, the paradigm of language ecology is identified by the following features: respect for human rights, equality of communication rights, multilingualism, the preservation of language and culture, the protection of national sovereignty, and the stimulation of foreign language learning (Tsuda 2008).

8 During the immigration emergency in October 2013, Bassam was in Lampedusa. He spent 20 days on the isle with only a short training course behind him. His main duty lay in immigrant reception, and he used Arabic to help in the best way possible. "I speak an Egyptian dialect which is easy for everyone to understand. The migrants - he says - are happy to hear an Egyptian, a nationality loved throughout the whole Arabic world. This reassures them." Bassam - the only CRI interpreter at that time - was in charge of the "first calls": the first phone calls for the migrants to contact their families once they had docked to reassure them that they had arrived safely. 
9 See the CNEL document, that is, the guidelines issued by the Italian National Council for the Economy and Employment in 2000 http://www.cnel.it/53?shadow_documenti=11362, and in 2009 http://www.cnel.it/271? shadow documento altri organismi=3366.

10 By working in such vulnerable contexts as migration emergency zones, mediators also witness distress, trauma and conflict and they too need and deserve psychological support, as widely examined by Beverly Costa (in press). 